\title{
EL PASADO DESHONROSO DE ISABEL ALLENDE
}

\author{
POR \\ VerónICA CoRTínez \\ University of California, Los Angeles
}

El auge de la novelística hispanoamericana de las últimas décadas se asocia exclusivamente con nombres de escritores masculinos. Los héroes indiscutibles del "boom" son, por voto unánime, Gabriel García Márquez, Carlos Fuentes, Julio Cortázar y Mario Vargas Llosa, para mencionar sólo a los que reaparecen en todas las listas, los cuatro miembros, como en las academias, "en propiedad". ${ }^{1}$

El repentino e inesperado éxito editorial de La casa de los espiritus, primera novela de Isabel Allende, desencadenó comentarios sorprendentes. Fabienne Bradu, por ejemplo, escribe en Vuelta:

Faltaba una mujer entre las filas del "boom" latinoamericano. Los europeos y los norteamericanos, patrocinadores de esta dudosa corriente sobre la cual depositaron sus ojos cansados de los horizontes locales, descubrieron y fabricaron a esta mujer-maravilla que tanto les hacía falta. Otras había, por cierto no tan exóticas como Isabel Allende, pero, ni modo, hasta ahora no les había gustado ninguna. (A propósito, ¿las conocerán?) El hecho es que escogieron a Isabel Allende, sobrina del fallecido presidente de Chile y exiliada en Caracas desde el golpe militar de 1973, para subirla en el trono de la consagración: la nueva reina de lo real maravilloso, a un lado del príncipe heredero: Gabriel García Márquez.

Para dar cuenta del fenómeno, Bradu recurre a explicaciones un tanto caprichosas como el exotismo, el exilio político y el famoso apellido. Otros críticos menos sarcásticos atribuyen el éxito de Allende (¡medido en dólares!) a sus predecesores masculinos. Ya es un lugar común afirmar, sin más, que las novelas de Allende no son más que una copia de las de García Márquez.

\footnotetext{
${ }^{1}$ Incluso críticos como Ángel Rama, que intenta responder con seriedad la pregunta “¿quiénes son los escritores del boom?", perpetúa con su sátira la famosa lista: "Un club que tiende a aferrarse al principio intangible de sólo cinco sillones y ni uno más, para salvaguardar su vocación elitista. De ellos, cuatro son, como en las academias, 'en propiedad': los correspondientes a Julio Cortázar, Carlos Fuentes, Mario Vargas Llosa y Gabriel García Márquez. El quinto queda libre para su otorgamiento: lo han recibido desde Carpentier a Donoso, desde Lezama Lima a Guimarães Rosa" (264).
} 
En este trabajo me propongo examinar esa reticencia a juzgar a Isabel Allende a partir de criterios que destaquen lo propiamente literario. A pesar de las apariencias, no creo que se trate simplemente de la consabida marginalización de la escritura femenina. No todas las escritoras hispanoamericanas han sido objeto de tal cantidad de sospechas y discriminaciones. No pienso tampoco que se trate, exclusivamente, de la envidia. El estigma de Allende se debe, en gran medida, a lo que podríamos llamar su "pasado deshonroso", y es justamente éste el que impide que su escritura se tome en serio. En Chile, el nombre de Isabel Allende alude de inmediato, no sólo al "fallecido presidente", sino a Paula, una revista femenina y, lo que es peor, una revista femenina "burguesa". Durante años, esta publicación quincenal incluía una columna titulada: "Civilice a su troglodita: los impertinentes de Isabel Allende". En 1974, la Editorial Lord Cochrane, patrocinadora de la revista, publicó una recopilación de estos artículos periodísticos acompañados de ilustraciones, todas de color fucsia. Creo que son precisamente estos artículos y, sobre todo, el libro los que han encasillado a Allende en el papel de escritor menor. Así, los críticos literarios "serios" la perciben como el prototipo del anti-intelectual: no sólo es mujer, sino también periodista y, para colmo, periodista frívola. Curiosamente, en lugar de renegar de ese pasado, ella misma se ha empeñado en cultivar esta imagen. Hasta el día de hoy, su firma va siempre acompañada nada menos que de una vistosa margarita. Pero, como veremos, en esta autodefinición radica su mejor defensa. El papel de "mujer sentimental" que asume Isabel Allende constituye una estrategia eficaz ya que, paradójicamente, la enlaza literariamente con Pablo Neruda, el escritor chileno por excelencia.

A primera vista, el libro Civilice a su troglodita consiste en una serie de recetas humorísticas para domesticar al hombre. El ingrediente principal de estas recetas es, claro está, la ironía. En esos artículos de Paula que ahora componen los once capítulos del libro, Allende aconseja a sus lectoras en materias como la alimentación, el trabajo, la amistad y el sexo, con el fin explícito de que ellas se instruyan en cómo retener al escurridizo cavernícola. Ya en la "Introducción", con su apelación directa a la lectora, se establece un franco tono de complicidad:

El propósito de este libro es que usted, estimada señora, pueda amaestrar su propio troglodita y convertirlo en un ser relativamente cómodo, higiénico, portátil y estético. Aunque nuestros propósitos son ambiciosos, consideramos que el esfuerzo vale la pena intentarse, ya que es mejor estar mal acompañada que sola. (6)

Además, desde el comienzo se nos asegura, con autoridad, que la estrategia es confiable: "Por experiencia personal puedo recomendar sólo un sistema. Hacerse la tonta" (10). Sin embargo, la simulación cautelosa implica sacrificios: "Para que él tome confianza, usted debe parecer estúpida de nacimiento y así le da a él la oportunidad de sentirse superior, lo cual no es fácil" (10). Para tener éxito, se debe adoptar fielmente el papel de la mujer tonta y débil:

Hay que ponerse a gritar cuando ve una abeja, desmayarse si queda atrapada en el ascensor, ponerse histérica con los incendios, los temblores y las arañas. Finja que no entiende los 
chistes, parezca inútil, gastadora y chismosa. Eso es lo que los hombres entienden por "feminidad" y es completamente inútil tratar de hacerlos cambiar de opinión. (11)

Sin embargo, si se lo considera en su totalidad, Civilice a su troglodita es, ante todo, un libro de amor. Con sus hipérboles e ironías, la mirada de Allende se aleja del panfleto feminista y acoge, con amabilidad, el ideal de los sentimientos. La única receta infalible para que los hombres "vivan en cautividad y se reproduzcan" es, nos dice, "que se sientan contentos" (6). Esa recopilación de artículos: "Está dedicada con amor, a quienes lo inspiraron: los hombres en general y uno en particular (Miguel Frías)" (3). En la "Introducción" reaparece la advertencia: "Para hacer feliz a su hombre, hay, por lo tanto, que empezar por amarlo" (6). Más aún, el libro termina con el siguiente consejo: "Ame a su hombre con locura" (92). Inexplicablemente, los críticos ignoran este marco significativo y le atribuyen al libro los calificativos de "humor hembrista" o "feminismo furibundo".

Desde la portada hasta la contratapa, Isabel Allende se mantiene fiel a la forma, un tanto preciosa y un tanto ridícula, de ese género que es el artículo de las revistas femeninas. No sólo respeta las leyes propias del género sino que, con frecuencia, las aprovecha en su discurso: "Aparte de las camisas de dormir exóticas, el perfume, las luces indirectas y otros trucos que recomiendan las revistas femeninas, es bueno que usted conozca, estimada lectora, una receta afrodisíaca" (31). En estos artículos de Paula se respetan las convenciones de diversos géneros en los que predomina lo sentimental; entre ellos, los novelones, las fotonovelas, las telenovelas, es decir, el melodrama: "En la práctica [el pijama] no sirve más que para huir en las revoluciones, los incendios y temblores y para las escenas finales de algunas fotonovelas en las que el galán relamido lleva en brazos al dormitorio a la casta doncella que desfallece de pasión" (34). Entre las ilustraciones abundan las flores, los corazones, las velas encendidas y los desnudos.

Es evidente que el libro se funda sobre generalizaciones y estereotipos. Éstos no pretenden una representación fidedigna del hombre y la mujer y, por lo tanto, no buscan una identificación con el lector. Las descripciones de ambos sexos son tan caricaturescas que facilitan el proceso de distanciamiento: "Las mujeres se entretienen pelándose mutuamente, hablando de sexo, de trapos y de niños, comprando, bailando apretado, viendo películas cebollentas y leyendo novelitas de amor latigudas. Los hombres se aburren indisimuladamente con estas cosas" (52).

Sin embargo, a partir del capítulo quinto, acerca "Del hombre y su alimentación", se introduce una vertiente en la que la clara exclusión de todos cede su lugar a una sutil inclusión de unos cuantos. El discurso de Allende abandona al público masivo y se dirige a un reducido grupo social, la clase alta: "Si usted le sirve aceite de bacalao con harina tostada en una copa de cristal cortado, se lo tomará feliz, en cambio, si le da el mejor cognac en un vaso de plástico, le provocará náuseas" (44). Más aún, Allende insiste: "Si usted le da arroz con huevo y le dice que es un 'Oeuf sovétique à la mode de Luxemburg', se lo come encantado. Si le da en la noche las sobras de arroz con otro huevo y le dice que es un 'Zaperlipopetz von Pilsner', creerá que está comiendo otra cosa" (43). Los hábitos descritos son, claramente, sólo los de la burguesía, como es el caso del veraneo: "Habiendo miles de kilómetros de costa en este país, todos tienen la idea de ir simultáneamente a los mismos lugares, de modo que cuando llegan deben abrirse paso a codazos, puntapiés y 
mordiscos en la sudorosa multitud" (88). ${ }^{2}$ El uso de "todos" para referirse a unos cuantos es significativo. La frívola exclusión clasista es lo que, en el fondo, rompe con la imagen de Isabel Allende como escritora seria. ${ }^{3}$

Es interesante que los críticos del libro oscilen entre el disimulo colectivo y la condena al olvido. Patricia Hart, por ejemplo, afirma: “... the early writings unaccompanied by contextualizations do not do justice to Allende's development at present, and to quote from them extensively would be misleading and unfair. For this reason I have chosen to simply make brief reference to the book in this appendix" (178). El uso de términos como "development" y "unfair" resulta curioso en este contexto pues sugieren la idea de progreso y redención; sólo al escribir sus novelas posteriores, Hart le perdona a Allende el pecado original de Paula.

A diferencia de la gran mayoría de los escritores hispanoamericanos que se saben parte de una novelística ya reconocida, Isabel Allende se ha dedicado a resaltar su condición de marginal: "Yo me siento como un pirata que se hubiera lanzado al abordaje de las letras a una edad en que otros cuidan a sus nietos. Escribo por impulso, porque me da placer. No tengo idea dónde se ubica el producto de mi trabajo"(Agosín 45). Ella misma ha contribuido a divulgar esa imagen de simple periodista, cuya cultura literaria es casi inexistente. El mito es conocido: un buen día Isabel Allende, ingenio lego, se sentó a escribir una carta y, sin darse cuenta, escribió una novela; tropezó con la literatura por casualidad.

Es evidente que esta autodefinición resulta enigmática, pues tiene dos caras que son, en apariencia, contradictorias: la espontaneidad ingenua, claro está, pero también la genialidad. Esa noción de escribir como en un vacío, sin modelos literarios y a partir sólo de las propias emociones, distinguiría a Allende de la mayoría de los escritores:

Escribo porque me gusta contar. Para mí es una fiesta diaria, es mi propia orgía perpétua [sic]. ... Por eso tal vez me va a ser muy dificil corregir los defectos de estilo, técnica o estructura que sin duda hay en mi obra, porque no pongo verdadero interés en corregirlos. Deseo contar bien, lo mejor que yo pueda, pero siempre de una manera natural, del corazón hacia afuera. Me interesa más tocar la emoción de mi lector, que provocar su admiración por mi estilo. Prefiero que llore, que se ría, que se involucre. ... Eso para mí es mucho más significativo que la opinión de los críticos o de los profesores de literatura. No es que la crítica no sea importante, sí lo es, pero mucho más importante es tocar el corazón de la gente que me lee, de la gente sencilla, del lector de la calle, él [sic] que no es especializado. Creo que tal vez en eso hay la deformación del periodista cuyo principal objetivo es comunicar. (Moody 53)

Desde la publicación de su primera novela, la crítica insiste en recordar el pasado periodístico de Isabel Allende y en juzgar su obra a partir de criterios del todo extraliterarios.

\footnotetext{
${ }^{2}$ Es cierto que, como me indica Roberto Castillo Sandoval, "todos" y "los mismos lugares" es una fórmula que también se aplica a otras clases sociales. Como él dice: "Si no es Cachagua, es Cartagena." Sin embargo, esto no invalida lo que digo.

${ }^{3}$ Basándose en una conferencia de la propia Isabel Allende, Teodora Remas sintetiza el problema de la siguiente manera: "Viene de una familia de lectores, dice, que "hasta ahora no se conforman conque [sic] yo haya salido una novelista. Querían que fuera una dama de sociedad"' (5). Podemos preguntarnos, ¿es que una dama de sociedad no puede ser novelista?
} 
El todopoderoso crítico literario de El Mercurio, Ignacio Valente, cuestiona su calidad y le exige un nivel que es, por definición, inalcanzable, pues se proyecta, cada vez, hacia el futuro: "En suma, esta tercera novela no dirime aún la cuestión sobre el rango novelístico de la autora, por mucho éxito que tenga, y por muy promisoria que sea. Habrá que esperar la cuarta obra como definición de su calidad precisa en términos de literatura" (E-3) y Valente subraya "literatura". La reseña, por cierto, se titula “ ¿Una gran novela frustrada?”. 4 Volodia Teitelboim, otra figura de autoridad en la cultura chilena, rechaza estos comentarios con vehemencia:

Isabel Allende no tiene que dar ningún examen. No tiene que comparecer ante ningún tribunal militar. Si se presentara a las universidades del dictador, donde los rectores designados son generales o individuos como Federici, que se jactan de no leer ningún libro, tal vez sería reprobada, o sea, condenada. Por eso es muy importante ante quién se da el examen. El hombre o la mujer tienen que dar exámenes todos los días. Su examinador es la vida. Y ella ha aprobado a esa alumna singularísima que se llama la novelista Isabel Allende. (33)

Sin embargo, Teitelboim mismo se refiere también, no sin paternalismo, a la posibilidad de un perfeccionamiento futuro en esa singularísima alumna: "Pero en la próxima obra no será la que escribió Eva Luna. Seguramente estará más madura como persona y como escritora" (33). Como se desprende de esta última frase, la novelista Isabel Allende, incluso después de su tercera novela, sigue estando a prueba.

Lo curioso es que la ambigua postura de Allende frente al campo de la literatura profesional sólo conduce a juicios más severos por parte de los críticos. Su respuesta ante esas acusaciones parece ser ingenua, pero al mismo tiempo constituye una fórmula eficaz para establecer su autoridad:

If you are trying to be a dancer and someone says it's bad because you dance like Nureyev, wouldn't you feel wonderful? That's the way I feel when people say I write like García Márquez. I think he's the great writer of the century, so it's wonderful if I'm compared to him - although I doubt he would like that. (Foster 45)

Es evidente que en estos juicios críticos abunda la contradicción. Si se le niega toda cultura literaria a Isabel Allende, ¿de dónde surgen entonces los parecidos de La casa de los espiritus con Cien años de soledad, o de Eva Luna con la novela picaresca? Mientras más se examinan esas novelas, menos creíble se vuelve la noción de Allende como escritora naïve. En toda su obra se advierte la huella textual, profundamente significativa, de la

\footnotetext{
${ }^{4}$ Sobre El plan infinito, Valente escribe: "Esta cuarta novela de Isabel Allende permite ya un juicio relativamente seguro sobre su status literario. Yo diría que la autora ha optado por el éxito, por la lectura masiva. ... La novela está llena de lugares comunes, de estereotipos sociológicos, históricos, psicológicos, que calzarían mejor en reportajes de magazine, en páginas de periodismo convencional. Hay algo sumamente folletinesco en esta novela. ... Isabel Allende ha dicho que no se le han subido a la cabeza los humos del éxito. Que lo pruebe rectificando. Que haga literatura con sus indudables dotes" (5).
} 
escritura de Pablo Neruda. Estos contactos apenas han recibido la atención de la crítica. Como se sabe, el epígrafe de La casa de los espíritus proviene precisamente de Neruda. En sus escritos y entrevistas, Allende se refiere, con frecuencia, a su poesía, y "La magia de las palabras" es un texto en el que desarrolla, de manera explícita, una idea del poeta (447). Lo que es aún más importante, el proyecto de Allende de introducir un "nuevo sentimentalismo" en la literatura fue ideado originalmente por Neruda. En "Sobre una poesía sin pureza", el poeta escribe:

Y no olvidemos nunca la melancolía, el gastado sentimentalismo, perfectos frutos impuros de maravillosa calidad olvidada, dejados atrás por el frenético libresco: la luz de la luna, el cisne en el anochecer, "corazón mío" son sin duda lo poético elemental e imprescindible. Quien huye del mal gusto cae en el hielo. (637)

Allende reformula esa misma idea en los siguientes términos: "Pero estoy dispuesta a desafiar el discurso literario masculino, que teme cualquier asomo de sentimentalismo como una subversión en el orden sagrado de la razón y del buen gusto. No pienso eludir los sentimientos, aunque para ello tenga que ir del brazo con la cursilería" (Teitelboim 31).

Civilice a su troglodita, con su subversión de la razón y del buen gusto y abiertamente del brazo con la cursilería, es un esbozo temprano de ese sentimentalismo que, más tarde, Allende desplegará en sus novelas y que asumirá con toda seriedad. En vez de ocultar los tempranos escritos periodísticos de Paula, ella los rescata sin prejuicios y los aprovecha en su literatura para crearse un perfil distintivo. No es casual que Inés, la protagonista de De amor y de sombra, sea periodista ni que Eva Luna se dedique a escribir telenovelas. Al referirse a las lectoras de Paula, Hart las define como "an old-fashioned 'ladies' magazines' audience" (178), situándolas, de alguna manera, fuera del ámbito de la literatura. Pero en esos artículos, Allende defiende con humor la experiencia amorosa. En toda su narrativa el amor desempeña un papel fundamental, y en ese sentimiento, en ese nuevo sentimentalismo, se advierte un optimismo poco común en la literatura contemporánea. ${ }^{5}$ En una entrevista con Teitelboim titulada "Isabel Allende delinea su concepción de la novela", la escritora afirmaba: "Me han advertido que en la literatura la esperanza puede ser peligrosa, no vaya a caer en la ingenuidad, en el panfleto o en la novelita rosa" (31). En Civilice a su troglodita, detrás de la ingenuidad y de la novelita rosa, está ya el núcleo de sentimientos que habrán de distinguir la narrativa de Isabel Allende.

\section{Obras Citadas}

Agosín, Marjorie. "Entrevista a Isabel Allende", Imagine 1/2 (invierno 1984), 42-56.

Allende, Isabel. Civilice a su troglodita: los impertinentes de Isabel Allende. Santiago: Editorial Lord Cochrane, 1974.

"La magia de las palabras", Revista Iberoamericana 132-133 (julio-diciembre 1985), 447-452.

\footnotetext{
${ }^{5} \mathrm{Al}$ respecto, ver el ensayo de Ernst Robert Curtius sobre lo excepcional, en el sentido estricto del término, de la poesía de Jorge Guillén.
} 
Bradu, Fabienne. "Reseña de De amor y de sombra", Vuelta 105 (agosto 1985), 44-45. Curtius, Ernst Robert. "Jorge Guillén." Kritische Essays zur Europäischen Literatur. Bern: A. Francke, 1954, 382-388.

Foster, Douglas. "Isabel Allende Unveiled", Mother Jones (diciembre 1988), 42-46.

Hart, Patricia. Narrative Magic in the Fiction of Isabel Allende. Diss. University of North Carolina at Chapel Hill, 1987. Londres y Toronto: Associated University Presses, 1989.

Moody, Michael. "Una conversación con Isabel Allende", Chasqui XVI/2-3 (noviembre 1987), 51-59.

Neruda, Pablo. Obras completas. Buenos Aires: Editorial Losada, 1973.

Rama, Ángel. La novela en América Latina: Panoramas 1920-1980. Bogotá: Procultura. Instituto Colombiano de Cultura, 1982.

Remas, Teodora A. "De la realidad nace la ficción", Andes Pacific. The Chilean Magazine $\mathrm{I} / 3$ (diciembre 1991), 5.

Teitelboim, Volodia. "Isabel Allende delinea su concepción de la novela", Plural 29/210 (marzo 1989), 29-33.

Valente, Ignacio. "Entre la novela y el folletín." Reseña de El plan infinito de Isabel Allende. "Revista de libros", El Mercurio (19 de enero de 1992), 5.

“¿Una gran novela frustrada?” Reseña de Eva Luna de Isabel Allende. El Mercurio (1 de noviembre de 1987), E-3. 
